\title{
Geophysical Prospecting
}

IN prospecting for minerals, oils, water, etc., 1 use can be made of the physical characteristics of the materials near the earth's surface. The methods at present adopted can be divided into four groups. The first group utilises the magnetic susceptibility of the materials, the second their density, the third their elasticity and the fourth group comprises various electric methods. The second group comprises the 'gravimetric' methods and the third the 'seismic'. In some cases two or more methods can be applied to the same area and so unwanted factors can be eliminated. The gravimetric method was made possible in 1888 when Baron von Eötvös published his work on the torsion balance. In 1914 Mintrop demonstrated experimentally the possibilities of the seismic methods. Prof. A. O. Rankine discussed the development of geophysical prospecting in his presidential address last year to Section $\mathrm{A}$ of the British Association at York.

In a paper read to the Institution of Electrical Engineers on April 7, J. M. Bruckshaw gave a detailed account of the electrical methods of surveying. As a rule, the interpretations of the electrical surveys are of a qualitative nature and in this respect they are not so good as the gravitational and seismic methods, which give indications of the depth and size of the material for which search is made.

There is now a tendency to develop more precise electrical methods with the object of placing them on a quantitative basis. The importance of making a preliminary geological survey and determining the resistivity of samples of the rock in the neighbourhood is now recognised. The results found in this way impose limitations on the use of the various methods that can be applied. If a known mass of ore occurs in the region under test, the interpretation of the results is greatly simplified by conducting the electrical survey directly over the known body.
As an example of the utility of geo-electrical prospecting, the case of a survey made by $\mathrm{Mr}$. Broughton Edge in Cyprus was described. Mineralisation was suspected from the indications of old Roman activities in the neighbourhood. This led to the ground being examined by means of four adits and three shafts, but without result. Within three days of starting the electrical surveys, the centre was plainly indicated by the equipotential lines. The interpretation was confirmed by driving two adits and these encountered a large pyritic mass, the upper end of which lay immediately below the centre. Although the surface of the ground was very rough the equipotential curves on the map were smooth.

In survey work, rocks and minerals are divided into two classes, metallic conductors and electrolytic conductors: Practically all minerals showing metallic lustre are in the first class. In nearly all methods of electrical prospecting, an equipotential line method is first employed as this takes very little time and locates the most promising areas. These areas do not necessarily represent mineral deposits, for bands of clay and graphite-impregnated schists, etc., yield the same type of anomaly as an ore body. In some cases, geophysics may differentiate between a mineral deposit and a band of clay, but it is generally the geologist who determines which of the indications are caused by ore.

The depth to which the ground can be examined depends on the kind of method used. In the resistivity methods, the ground examined penetrates to a depth approximately equal to the distance between the electrodes. With great depths the results obtained are difficult to interpret. As a rule, it is not convenient to use currents greater than five amperes. Good results are sometimes obtained by using high-frequency alternating currents.

\section{Obituary}

\section{Prof, Victor Goldschmidt}

CCIENCE has to deplore the loss of another of $\checkmark$ her 'grand old men', Germany one of her most distinguished sons, and the world of culture at large one of the most accomplished, versatile and beneficent of its exponents, in the passing on May 8 of Prof. (Herr Geheimrath) Victor Goldschmidt, honorary professor of mineralogy and crystallography at the University of Heidelberg, at the ripe age of eighty years. His name has long been a household word with the small, but now happily increasing, coterie of workers in crystallography, which he was fond of calling the "Queen of Sciences" ; and he was never tired of expressing his intense delight in the wonderful beauty of crystals. Yet so wide were his interests that in many other subjects he was almost equally distinguished, particularly ethnography, astronomy, physiology, colour in art, and tone and harmony in music. Having inherited great wealth-sadly depleted afterwards by the War-he was able to advance the interests of his subjects to an exceptional degree, and became a 'pious founder' in the truest sense of the term.

Born in Mainz on February 10, 1853, of Jewish stock, in the year 1871 he became a student of the Gewerbakademie of Berlin. Then from 1872 until 1878 he attended the celebrated Bergakademie of Freiberg, and during his last three years there acted as an assistant. In order to acquire further experience, however, he migrated in 1878 to the School of Mineralogy and Crystal- 